was frequented throughout each day, and the papers which were read were followed with interest by large audiences, and gave rise to a number of animated discussions.

Prof. Sadler opened on the morning of January 7 with an examination of "The Relation of Elementary Schools to Technical Schools, Day and Evening." An abridgment of his paper appeared in NATURE of January 13 , so it is unnecessary to make more than a brief reference to it here.

Some of the chief difficulties in the way of further education for children from primary schools were traced by Prof. Sadler to the snapping by the factories of the educational tradition associated with the old apprenticeship system. Too many English parents now think that a child's education ends when he leaves the elementary day school, while our employers and foremen have lost the sense of responsibility for the further education of the young people in their employment. Substantial reform can only be attained after a completion of the change in public opinion now in progress, and by the re-enlistment of the great employers to the cause of continued education. As regards the legislative measures that will eventually be required to extend the powers of local authorities in dealing with technical continuation classes, and to secure regularity of attendance, Prof. Sadler advocated the recommendations of the Consultative Committee of the Board of Education.

Mr. James Baker contributed to this discussion an account of the system of continuation schools in Austria, from which it appears that apprentices to a great variety of trades are bound to attend regularly the industrial schools of their townships after leaving the elementary schools at the age of fourteen, and that employers are bound to allow the necessary time for such attendance.

Mr. J. H. Reynolds urged that the half-time system demanded by employers must be postponed until after the children's fourteenth year.

On Friday afternoon, January 7, Mr. Max Muspratt, J.P., C.C., opened the discussion on cooperation between employers and education authorities. He cited (as Prof. Sadler had also done) the example of certain large firms (Messrs. Brunner, Mond and Co., Northwich; Messrs. Lever Brothers, Port Sunlight; and the United Alkali Co., Widnes) the directors of which bound all their young employees to attend evening classes up to the age of eighteen or nineteen, the firms paying the fees. This system of friendly compulsion is rendered possible by the fact that the large works in question practically monopolise the labour market in their respective areas: but in the larger towns, owing to the difficulty of bringing the hundreds of offices and firms into line, the only solution is to give powers to local authorities to start some form of compulsory attendance at evening schools up to the age of sixteen for office boys and apprentices. In Liverpool the big engineering shops, e.g. of the Dock Board and the White Star and Cunard lines, offer a variety of inducements to apprentices to continue their education, and a similar beginning has been made in a variety of other trades (building, painting, plumbing, \&c.).

Mr. V. A. Mundella described the scheme under which the Associations of Shipbuilders and Engineers of Sunderland cooperate with the Sunderland Technical College in the training of engineering apprentices.

Mr. R. Wallace, of the Wallsend Shipway and Engineering Company, and vice-chairman of the Wallsend Education Committee, said that any attempt to educate the masses bevond their capabilities would not benefit them, and would be a waste of the nation's resources. They were dissatisfied with elementary education, and with good cause. What they needed was skilled handicraftsmen.

On the morning of January $8 \mathrm{Mr}$. J. C. Medd opened the discussion on "Education Abroad and in England," and we hope to find space for an abridgment of his paper in another issue. Mr. Medd considers that the facilities for technical and scientific instruction are as great in England as in Germanv, but the German has the advantage in the better quality of the pupils who attend those colleges and schools. In elementary education there is a great need for more practical instruction, some relaxation of the regulations as to building and equipment for manual instruction and domestic science, and the introduction of a system of supplementary courses.

NO. 2099, VOL. 827
Mr. Otto Siepmann attributed the high average excellence of elementary education in Germany partly to the thorough six-years' training which intending teachers receive in the training colleges, and partly to the fact that the field from which the teachers are drawn is not denuded of its most gifted scholars by any "educational ladder" which leads to other spheres of activity. In the secondary schools, also, individual prominence is sacrificed to raise the common average. All subjects are done in form, and practically the whole form is promoted from one stage to the next. Thus a particular aptitude for a special subject is never developed at school, but the German system ensures for every boy a sound general education. At the universities all this is changed, and the freedom which students are allowed in the choice of subjects, the general lack of supervision and of interim examinations, react favourably upon their work. They carry into life an active interest in some branch of knowledge, which they frequently pursue as long as they live.

Limitations of space prevent any reference to the discussions on art subjects and physical training, and allow merely brief reference to two other topics.

Miss Burstall admitted that the young people who now leave our secondary schools are to a large extent lacking in self-reliance and the power of independent work. She attributes this result to the pressure of the examination system, which forces the teacher, almost in self-defence, to do for the children half the work of gaining, arranging, and applying knowledge. Independent work by the scholars requires more time, which can be got only by reducing the number of subjects studied in any one year. The first thing to aim at, therefore, is to lighten the pressure of examinations.

Mr. W. B. Steer urged that much could be done to encourage independent habits of study by substituting silent reading, followed by keen questioning, for the ordinary reading lesson. At present excessive teaching leaves scant time for learning. Mr. E. E. Unwin spoke of the leisurehour work and other forms of independent study practised in Bootham School, York.

On "The Relation of the State to the Training of Teachers of Domestic Subjects, and their Relation to the University," Prof. Smithells urged that the time had come for incorporating the training schools of cookery and other domestic subjects in an improved scheme for the general training of teachers, and for treating this important branch of work with less parsimony than hitherto. The domestic training schools should form an integral part of the women's training colleges, though not necessarily in the same building. At the same time, there was no reason except that of expense why a fuller curriculum of training in branches of knowledge relating to these subjects should not be provided in our modern universities, which already function as day training colleges for teachers seeking a more extended knowledge and the attendant degree iil arts or science.

Miss M. Atkinson spoke of the introduction in London King's College for Women of two courses in domestic science, one for undergraduates and the other for postgraduate students. It was necessary in domestic economy to draw a sharp line somewhere between the minimum of hygienic knowledge and domestic skill, which should form a part of the education of everyone, and the specialised technique to be demanded of those who proposed to be experts in the subiect; but in resard to the latter class especially, the basis of the training should be real and not sham science. The preliminary studies in physics, chemistrv, physiology, and economics should consequentiy be provided bv first-vear courses at the university in these subjects, exactly as for students of engineering or medicine.

\section{THE ETHNOLOGY OF CALIFORNIA.}

THE University of California, continuing its useful work of investigating the ethnology and languages of the now rapidly disappearing Indian tribes of that State, pub lishes in the third part of the fifth volume of its Proceedings a monograph, by Mr. P. E. Goddard, on the Kato tribe, a branch of the Athapascan race on the Eel River. They have undoubtedly assimilated much of their culture from contact with the Pomos to the south and the Yukis 
to the east and west; but they still retain so much of their primitive folk-lore and beliefs that they deserve special examination. While their legends of the origin of fire and the sun are more or less common to other members of the group, their accounts of the creation and the deluge are peculiar to themselves. In the first, the earth with its great long horns raises itself from the primeval waters. The god Nagaitcho takes his seat upon it, places its head in the direction in which it should lie, and spreads clay between its eyes and upon each horn. Finally, in this he plants trees and other vegetables, and moulds the mountains and valleys.

In a second myth the gods Nagaitcho and Thunder cause the old, worn-out sky to fall, and replace it with a new firmament with four portals and four supporting columns, preparing at the same time summer and winter trails for the sun. Then follows a deluge, and the creation of fish and beasts of the sea. They then make man out of clay and woman out of one of his legs. In another myth Coyote steals the sun, which he finds tied up in a blanket in the house of an old woman. Out of pieces of the sun he creates the moon and stars. This series of myths, with other folk-tales, has been taken down from the lips of Bill Ray, who is apparently the last member of the tribe acquainted with the race traditions. Mr. Goddard has published the legends in the native language with an interlinear translation, and adds a free version which renders them intelligible. He admits that the record is fragmentary, and that they have probably lost some of their primitive form; but even with this qualification they will prove of interest to students of comparative mythology.

\section{SOME APPLICATIONS OF MICROSCOPY TO MODERN SCIENCE AND PRACTICAL KNOWLEDGE.}

THE time is past when a man can expect to make any real contribution to knowledge by spreading his observations over the whole vast range of microscopic objects. In these days, in which the output of research on every subject is enormous, and is increasing rather than diminishing, a man is more likely to make progress and do useful work by taking up a special line and sticking to it. Speaking for those who work with, rather than at, the microscope, I would advise everyone who wishes his work to be fruitful in results to have a hobby of his own. In making this suggestion, I do not mean that we are all to become narrow specialists, interested in nothing but our own particular subject. Specialisation in work and in research does not necessarily mean specialisation in knowledge or in interests. The great value of such a club as ours is that by bringing together people occupied in different branches of work it enables one man to know what another man is achieving in a different line, thereby at once widening his outlook and stimulating him in his own work by producing a healthy spirit of emulation.

My advice, therefore, to the microscopist would be that he should aim at wide knowledge and diffuse interests, but should concentrate his activities and focus his attention on his own particular pet hobby, so that, by mastering a branch of natural knowledge, he may find himself in a position to advance it. However limited the field of study may be, however insignificant the objects may appear, yet something can always be found which, on the one hand, will illustrate some important and fundamental principle, or, on the other, will prove ultimately to have some direct or indirect bearing on human life and its needs. Let me give two instances in support of this statement. To the so-called practical man it may seem a very trivial occupation to worry about such things as Foraminifera, however beautiful their shells may be. Yet these tiny creatures, living in a sphere apparently so remote from our own, furnish wonderful illustrations of the powers and activities of primitive living matter, and Mr. Earland has recently directed our attention to the remarkable property they exhibit of selecting particular materials for building up their houses. This is a most interesting fact, well worthy of further study, especially by experimental

1 From the presidential address delivered to the Quekett Mirroscopical Club on May 7, rgog, by Prof. E. A. Minchin, and published in the Journal of the Club for November, rgog.

No. 2099, VOL. 82] methods, for it indicates that the most primitive and form less living matter possesses faculties of a kind which we term in higher forms of life instinct or intelligence. Again, a reputation for being an expert on, let us say, fleas, may provoke a smile from the uninstructed; but in view of the proved connection between fleas and human disease, especially plague, these paltry insects have now assumed very great importance as objects of study, and we find detailed descriptions of them in the reports of Government commissions. As Lord Crewe remarked in a recent speech, we commonly speak of any very trivial annoyance as a flea-bite; but we know now that in certain circumstances a flea-bite may cost a man his life. Small wonder, then, that fleas have become important objects of study to mankind.

This question of fleas and plague reminds me that I am here, not to preach a sermon, but to give an address, by recalling to my mind the subject which I propose to discuss to-night, namely, some of the remarkable advances that have been made during the last few years in our knowledge of human diseases caused by microscopic parasites. This is a subject which has now grown to such vast proportions that I must confine myself of necessity to a small part of it, namely, the diseases caused by Protozoa. As examples, I shall deal more especially with malaria, sleeping sickness, and yellow fever.

Malaria is a disease which was well known to the ancients, and is still very rife in many parts of Europe. It appears to have been prevalent formerly in the fen districts of England, but to have died out there from some unexplained reason. It is estimated by Prof. Ronald Ross to cause from a quarter to half the total disease in the tropics. It occurs under at least three forms, known commonly as tertian, quartan, and pernicious malaria, each of them easily distinguishable clinically, and due to distinct species of the parasite differing from one another in morphological characters, but similar in the general features of their life-cycle.

Until comparatively recent times nothing whatever was known of the nature of malaria or the manner in which it was acquired. It was generally believed that it was due to a poisonous miasma which arose from swamps and marshes, a notion conveyed in the name malaria- "bad air." This miasma theory is very prevalent in literature: for instance, in such a work as Dickens's "Martin Chuzzlewit," where the unfortunate settlers in Eden are supposed to contract fever by breathing the exhalations of the swamps.

The scientific study of malaria may be dated from 1880 , when the parasite was discovered in the blood of fever patients by Laveran, then a military surgeon in Algiers. Laveran examined the blood microscopically, and observed the principal nhas ${ }^{\wedge}$ of the parasite. It was, however, some years before Laveran's parasite was accepted as the cause of malaria, though it ultimately obtained universal recognition. Even then it remained a mystery how the parasite cot into the blood, and many still held to the miasma theory. It was supposed by some that the parasite passed out of the body and produced cysts or spores which could be disseminated by the wind, iust as the cysts of many Infusoria are known to be carried by aërial currents, and that by inhaling these air-borne germs the disease was acquired. Others sought for the source of the infection in the contamination of drinking-water.

It remained for a countryman of ours to discover the true method of infection. Prof. Ronald Ross, then in the Indian Medical Service, experimented first with the very similar malarial parasites of birds, and found that the infection was taken from one bird to another by mosquitoes of the genus Culex. Similar experiments on human malaria gave at first negative results, until it was discovered that the necessary intermediate host of human malaria was a mosquito belonging to quite a different genus, Anopheles. These experiments were confirmed by manv investigators in all parts of the world, and led to results which may be stated in two propositions, one positive, one negative, first premising that by a malarial infection is meant a new infection, not a relapse in a person oreviously infected.

(I) Malaria can be and is conveved from sick to healthy persons by the agency of mosquitoes. 